\title{
DIFFERENT MODES OF ELECTRODEIONIZATION OF CESIUM FROM AMP-PAN
}

\author{
Ch. Mahendra ${ }^{1}$, P.M. Satya Sai ${ }^{2}$, C. Anand Babu ${ }^{3}$ \\ ${ }^{1}$ Fast Reactor Technology Group, Indira Gandhi Centre for Atomic Research, Kalpakkam-603102, India \\ ${ }^{2}$ Waste Immobilization Plant, Bhabha Atomic Research Centre, Kalpakkam-603102, India \\ ${ }^{3}$ Sri Venkateswara College of Engineering, Chennai-602105, India;
}

\begin{abstract}
Electrodeionization (EDI) process was investigated for the recovery of Cs from AMP-PAN (Ammonium molybdophosphate Polyacrylonitrile). Ammonium sulphate solution was used as an eluant for the recovery of cesium from AMP-PAN with simultaneous regeneration of AMP-PAN. Two different modes of operation were studied in which eluant is passed through different compartments of the electrodialysis cell. One of the key parameters affecting the process like current density on Cs recovery was studied. The transport phenomena of the ions in the cell were explained using Nernst-Plank equation. Migration diffusion coefficients of the ions were determined by reducing the Nernst-Plank equation to migration term.
\end{abstract}

Keywords: Cesium, AMP-PAN, electrodeionization, recovery, regeneration.

\section{INTRODUCTION}

$\mathrm{Cs}^{137}$ is one of the predominant fission isotopes issuing in the High Level Waste (HLW) in nuclear reprocessing of spent fuel. Cs-137 being radioactive in nature finds application in sterilization of medical accessories, food preservation, brachytherapy, blood irradiation, hygienization of sewage sludge etc. Owing to its several medical and industrial applications, separation of Cs from nuclear waste in pure form would be a potential step. Ammonium molybdophospahte Polyacrylonitrile (AMP-PAN) has been extensively studied for selective uptake of Cs from acidic solutions (Sebesta, Todd etal., Tranter et. al). Regeneration of AMP-PAN should be done with high concentration of eluant (ammonium salt solution) to recover sorbed cesium. Recovery of Cs in pure and concentrated form from high concentrated ammonium solution requires further operations with other ion exchange materials or other methods.

Ammonium molybdophosphate (AMP) is a well known ion exchange resin with high Cs selectivity among many ion exchangers (Y. Park et. al). Because of its microcrystalline nature, AMP was not suitable for column operations. Several researchers tried different combinations of AMP with different organic polymers like silica gel, $\mathrm{Al}_{2} \mathrm{O}_{3}$ and zirconium phosphate for a column suitable AMP. Sebesta developed AMP-PAN by immobilizing ammonium molybdophosphate (AMP) on polyacrylonitrile (PAN) polymer support. AMP-PAN has been extensively studied for removing ${ }^{137} \mathrm{Cs}$ from acidic and high salted radioactive waste stream (T.J. Tranter et al, T.A. Todd et al). It was reported high distribution coefficients were observed for AMP-PAN in selectively separating Cs from other fission products (T.J. Tranter et al).
Ammonium salts only replaces cesium on the exchanger or regenerates AMP-PAN. Generally high concentrated salts are used for regeneration of ion exchange resins. Regeneration of AMP-PAN with high concentrated salts not only reduces the life of the material (high alkalinity) but also results in a dilute solution of $\mathrm{Cs}$ with high concentration of ammonium ions. Again some other sorbent or process should be opted for recovery of Cs from high concentrated ammonium ions.

In view of these difficulties, electrodeionization (EDI) process was investigated for the separation of cesium from simulated high level liquid waste which should minimize the waste generation and to reduce the steps involved in the process.

\section{MATERIALS AND METHODS}

\subsection{Experimental Details}

Cesium from simulated HLW is passed through an ion exchange column (containing AMP-PAN) which separates Cs from other fission products. The sorbed AMP-PAN is kept in an electrodialysis cell for recovery of cesium in pure form. The electrodialysis cell was operated in two different modes for the recovery of Cs from AMP-PAN. In mode-I, eluant (ammonium sulphate) was passed as anolyte and in mode-II, eluant is passed directly through the ion exchange resin in the middle compartment of the electrodialysis cell as shown in Figures 1 and 2. In both modes of operation, eluant $\left(\left(\mathrm{NH}_{4}\right)_{2} \mathrm{SO}_{4}\right)$ containing $\mathrm{NH}_{4}{ }^{+}$migrates on application of electric potential towards cathode. Since cathode is negatively charged, it attracts positive charged ions only. On its way towards cathode, $\mathrm{NH}_{4}{ }^{+}$ions replace sorbed $\mathrm{Cs}^{+}$on AMP-PAN and the exchanged $\mathrm{Cs}^{+}$is now available for migration towards cathode. Thus $\mathrm{Cs}$ on the AMP-PAN is recovered and concentrated in cathode compartment by 
application of electric potential. Some ammonium was also migrating along with Cs towards cathode which will convert to ammonia gas form due the generation of hydroxyl ions at the cathode surface. Thus pure Cs can be obtained by EDIX in limited number of operations. The parameters affecting the process have been studied and optimized the process.

The transport of ions in the packed bed of electrodialysis cell is explained based on Nernst- Plank ion transport model in terms of convection, diffusion and migration. Migration term of Nernst-Plank equation was in the determination of migration diffusion coefficient.

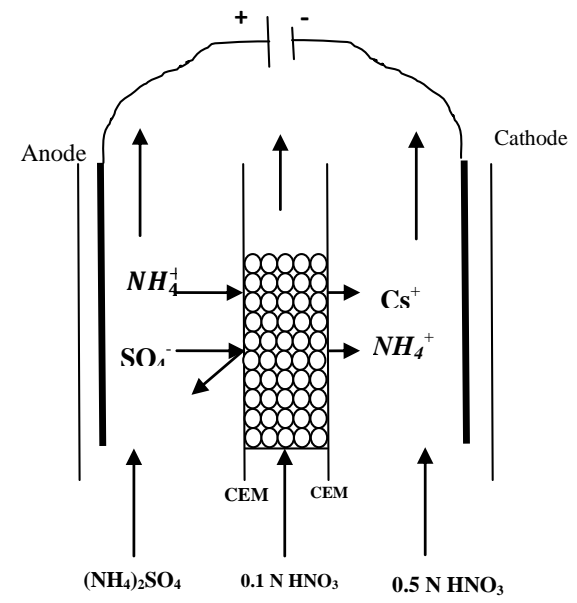

Fig 1 Operation of cell in mode-I

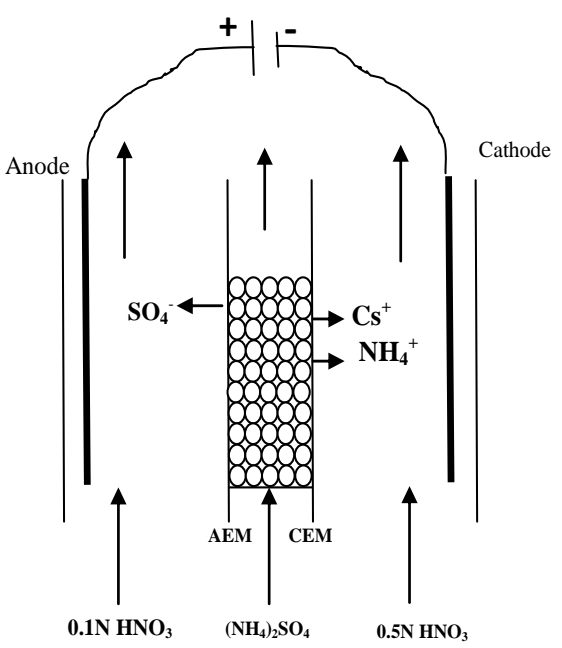

Fig 2 Operation of cell in mode-II

At Anode: $\quad 2 \mathrm{H}_{2} \mathrm{O} \rightarrow \mathrm{O}_{2}+4 \mathrm{H}^{+}+4 \mathrm{e}^{-}$

At Cathode: $4 \mathrm{H}_{2} \mathrm{O}+4 \mathrm{e}^{-} \rightarrow 2 \mathrm{H}_{2}+4 \mathrm{OH}^{-}$

\section{RESULTS AND DISCUSSION}

The Nernst-Plank relationship describing the transport of ions through a homogenous bed of ion-exchange resin was used by several researchers for electrodeionization (P.B. Spoor et al., Y.S. Dzyazko et. al, A. Mahmoud et. al) where, values with an overbar belong to solid phase. The first term on the right hand side describes the diffusion of ion $i$ with concentration $\bar{C}_{i}$ and diffusion coefficient $\bar{D}_{i}$. The second term is for the migration of ion $i$ with valence state $\mathrm{z}_{\mathrm{i}}$ and mobility $\bar{u}_{i}$. The bed potential gradient is denoted by $\operatorname{grad} \varphi$. The third term describes the movement of pore liquid within the ion-exchange particles.

It was observed that diffusion and convection effects are negligible compared to migration in presence of sufficient electric field. All the terms in the Nernst-Plank equation reduces to the migration term for ion transport in electrodeionization cells.

$$
\overline{\mathrm{N}}_{\mathrm{Cs}}=\mathrm{z}_{\mathrm{i}} \overline{\mathrm{C}}_{\mathrm{i}} \overline{\mathrm{u}}_{\mathrm{i}} \operatorname{grad} \varphi
$$

The mobility of the ions in the packed bed, $\bar{u}_{i}$, is defined by equation 3:

$$
\bar{u}_{i}=\frac{\bar{D}_{i} F}{R T}
$$

The equation (2) becomes

$$
\overline{\mathrm{N}}_{\mathrm{Cs}}=\mathrm{z}_{\mathrm{i}} \overline{\mathrm{C}}_{\mathrm{i}} \frac{\overline{\mathrm{D}}_{\mathrm{i}, \mathrm{eff}} \mathrm{F}}{\mathrm{RT}} \operatorname{grad} \varphi
$$

The migration of metal ions to the cathode compartment can be analyzed using the empirical model of resin regeneration proposed by P.B. Spoor et al for electromigration of nickel. The model assumes first order kinetics with respect to metal ion concentration in the resin and predicts the flux of the metal ion in terms of the maximum amount of ions extracted from the resin, which can be determined experimentally. Using this model, the experimental curves are fitted to the following exponential equation to predict $\mathrm{n}_{\mathrm{Cs}}$, the amount of cesium present in the catholyte:

$$
\mathbf{n}_{\mathrm{Cs}}=\mathbf{n}_{\mathrm{Cs, \operatorname {max }}}\left(\mathbf{1}-\mathbf{e}^{-\mathbf{k}_{\mathrm{m}} \mathrm{t}}\right)
$$

where, $\mathrm{n}_{\mathrm{Cs} \text {,max }}$ is the maximum amount of Cs present in the catholyte at the end of the experiment and $\mathrm{k}_{\mathrm{m}}$ is the mass transfer coefficient, a model parameter.

The cesium flux from the bed can be calculated using the derivative of equation 5 .

$$
\mathbf{N}_{\mathrm{Cs}}=\frac{1}{A_{\text {bed }}} \frac{\mathbf{d n}_{\mathrm{Cs}}}{\mathrm{dt}}=\frac{\mathbf{k}_{\mathrm{m}} \mathbf{n}_{\mathrm{Cs}, \mathrm{max}}}{A_{\text {bed }}} \mathbf{e}^{-\mathbf{k}_{\mathrm{m}} \mathrm{t}}
$$

\section{Calculation of effective diffusion coefficient}

The effective diffusion coefficient of cesium in the bed, $\overline{\mathrm{D}}_{\mathrm{Cs} \text {, eff }}$ can be found out using the migration term of Nernst-Planck equation (Spoor et al),

$$
N_{C s}^{0}=\mathrm{z}_{\mathrm{Cs}} \overline{\mathrm{C}}_{\mathrm{Cs}}^{0} \frac{\overline{\mathrm{D}}_{\mathrm{Cs}, \mathrm{eff}} \mathrm{F}}{\mathrm{RT}} \operatorname{grad} \varphi
$$

$$
N_{i}=\bar{D}_{i} \frac{d \bar{C}_{i}}{d x}+z_{i} \bar{C}_{i} \bar{u}_{i} \operatorname{grad} \varphi+v \bar{C}_{i}
$$


where, $N_{C s}^{0}$ and $\overline{\mathrm{C}}_{\mathrm{Cs}}^{0}$ are the possible cesium flux and concentration of $\mathrm{Cs}$ in solid phase at time $\mathrm{t}=0$.

The effective diffusion coefficient, $\bar{D}_{C s, e f f}$ can be calculated from equations 6 and 7 as

$$
\bar{D}_{C s, e f f}=\frac{n_{c s, \text { max }} k_{m}}{A_{\text {bed }}} X \frac{R T}{z_{C s} F|\overline{C s}|_{0} \nabla \varphi}
$$

where subscript $\mathrm{t}$ refers to time $\mathrm{t}$. The effective diffusion coefficient, $\bar{D}_{C s, e f f}\left(\mathrm{~m}^{2} / \mathrm{s}\right)$, is calculated at time $\mathrm{t}=0$.

\subsection{Effect of Current Density}

Cesium recovery form AMP-PAN in mode-I was studied for an eluant concentration of $10000 \mathrm{ppm} \mathrm{NH}_{4}{ }^{+}(0.27 \mathrm{M}$ $\left.\left(\mathrm{NH}_{4}\right)_{2} \mathrm{SO}_{4}\right)$, varying the current density from 20 to 30 $\mathrm{mA} / \mathrm{cm}^{2}$. Using the cowan plots, the limiting current density was found to be $35 \mathrm{~mA} / \mathrm{cm}^{2}$ for the studied conditions. Figure 3 shows the concentration of cesium recovered by migration in cathode compartment for the different applied current densities.

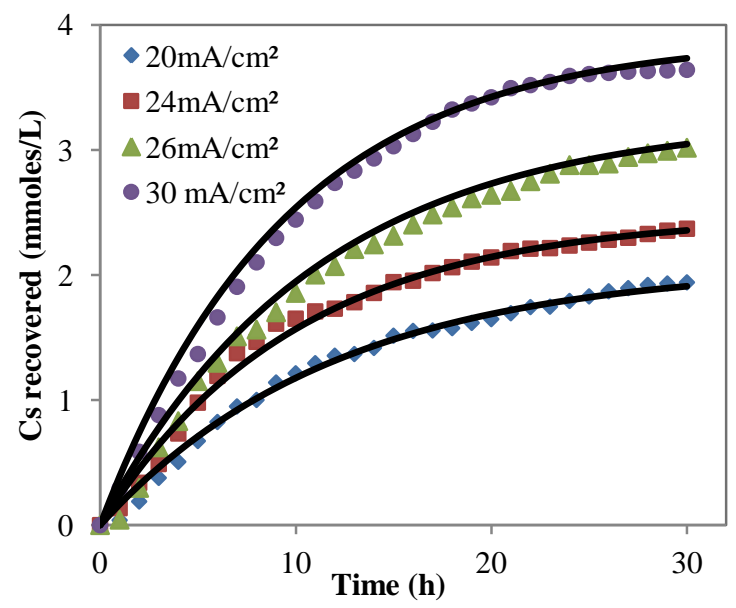

Fig 3 Cs recovery in catholyte for different current densities (Eluant Conc. $=0.27 \mathrm{M} \mathrm{NH}_{4}^{+}$)

From Figure 3, it was observed that Cs recovery increased with time for all the studied current densities. The recovery is rapid in the first $15 \mathrm{~h}$ and then only little increase in recovery was observed upto $30 \mathrm{~h}$. From $15 \mathrm{~h}$ to $30 \mathrm{~h}$ of operation, only $10 \%$ of the total recovered Cs could be eluted from the AMP-PAN for all the studied current densities. The total recovery of Cs increased from 1.94 to $3.64 \mathrm{mmoles} / \mathrm{L}$ with increase in current density from 20 to $30 \mathrm{~mA} / \mathrm{cm}^{2}$. Further increase in current density was restricted by concentration polarisation effects. The percentage recovery of $\mathrm{Cs}$ by migration to catholyte for different current densities was shown in Figure 4.

With increase in current densities from 20 to $30 \mathrm{~mA} / \mathrm{cm}^{2}$, the total Cs recovered in catholyte increased from 38 to $74.5 \%$. The migration of ions in electrodialysis cell increases with increase in current, which had increased the Cs recovery percentage from AMP-PAN. Negligible amounts of Cs were observed in anode and middle compartment, which led to the conclusion that there was no diffusion of Cs across the ion exchange membranes.

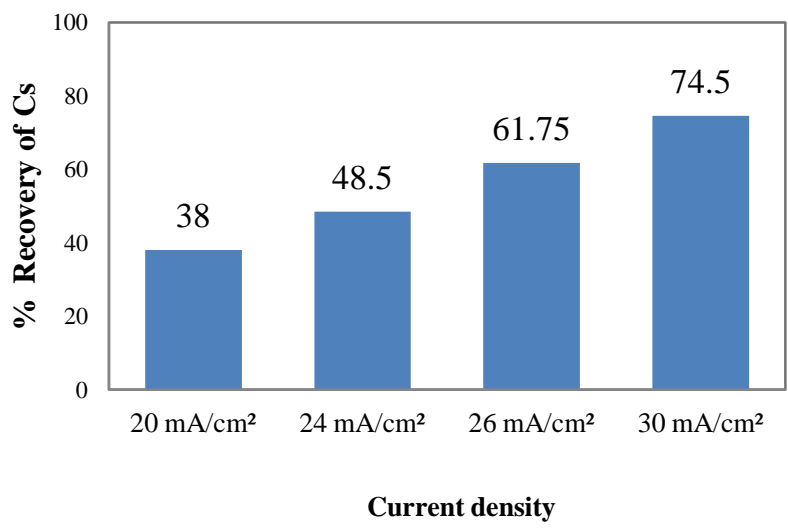

Fig 4 Total recovery of Cs from AMP-PAN for different current densities

Application of Nernst-Planck equation to describe the recovery of Cs from AMP-PAN by migration resulted in the determination of the effective diffusion coefficient of Cs at time $\mathrm{t}=0$ (equation 5.8) From Table 1 , it was seen that $\mathrm{Cs}$ migration diffusion as well as mass transfer coefficients increased with increase in current density.

Table 1: Migration diffusion coefficients in mode-I operation

\begin{tabular}{|c|c|c|c|c|}
\hline $\begin{array}{c}\text { Curretnt } \\
\text { density } \\
\left(\mathrm{mA} / \mathrm{cm}^{2}\right)\end{array}$ & $\begin{array}{c}\mathrm{n}_{\max } \\
(\text { moles })\end{array}$ & $\begin{array}{c}\text { grad } \varnothing \\
(\mathrm{V} / \mathrm{m})\end{array}$ & $\begin{array}{c}\mathrm{k}_{\mathrm{m}} \mathrm{X} \\
10^{-5} \\
\left(\mathrm{~s}^{-1}\right)\end{array}$ & $\begin{array}{c}\mathrm{D}_{\text {eff }} \mathrm{X} \\
10^{-9} \\
\left(\mathrm{~m}^{2} / \mathrm{s}\right)\end{array}$ \\
\hline 20 & 2.08 & 800 & 2.31 & 0.92 \\
\hline 24 & 2.48 & 740 & 2.78 & 1.41 \\
\hline 26 & 3.26 & 640 & 2.53 & 1.98 \\
\hline 30 & 3.9 & 640 & 2.92 & 2.73 \\
\hline
\end{tabular}

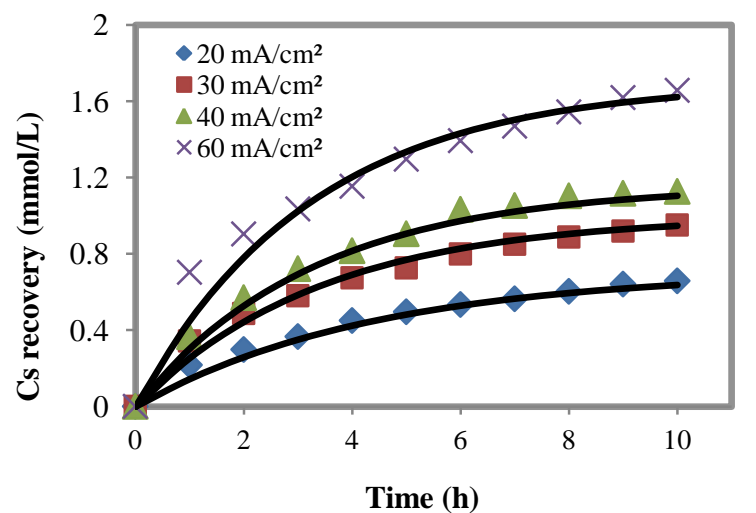

Fig 4 Cs recovered by convection for different current densities $\left(\mathrm{NH}_{4}^{+}=0.27 \mathrm{M}\right)$

In the mode-II of EDI process, application of current across the cell results in the migration of anions and cations through the middle compartment towards anode and cathode, respectively. The eluant containing $10000 \mathrm{ppm}$ $\mathrm{NH}_{4}^{+}$flowing in the middle compartment replaces the cesium ions on the AMP-PAN resin, when it comes in contact with the resin. Part of the total eluted cesium from the resin migrates towards the cathode compartment under 
the applied current and the remaining was convected by the eluant flowing through the middle compartment on once through basis. The recovery of cesium from cesium sorbed AMP-PAN was determined at different current densities ranging from $20 \mathrm{~mA} / \mathrm{cm}^{2}$ to $60 \mathrm{~mA} / \mathrm{cm}^{2}$. The amount of cesium recovered with time from the cathode compartment was shown in Figure 5 for different current densities.

From Figure 5, it can be seen that migration of cesium to the cathode compartment increased with increase in the current density from 20 to $60 \mathrm{~mA} / \mathrm{cm}^{2}$, due to increased ion movement. The migrated cesium was about 0.6 millimoles for $20 \mathrm{~mA} / \mathrm{cm}^{2}$ and it increased to more than 1.6 millimoles for $60 \mathrm{~mA} / \mathrm{cm}^{2}$ in $10 \mathrm{~h}$ of operation. The total amount of cesium recovered from different compartments was shown in Figure 6.

From Figure 6, it can be seen that the total cesium convected by the eluant through the middle compartment decreased with increase in the current density. Increase in migration rate at higher current densities decreased the convection of cesium ions by the eluant. After $10 \mathrm{~h}$ of operation, both cesium migration and convection were found to be negligible.

As the middle compartment was separated from the anode compartment with an anion exchange membrane, which restricts the migration of cations towards anode, negligible amounts of cesium were found in the anode compartment.

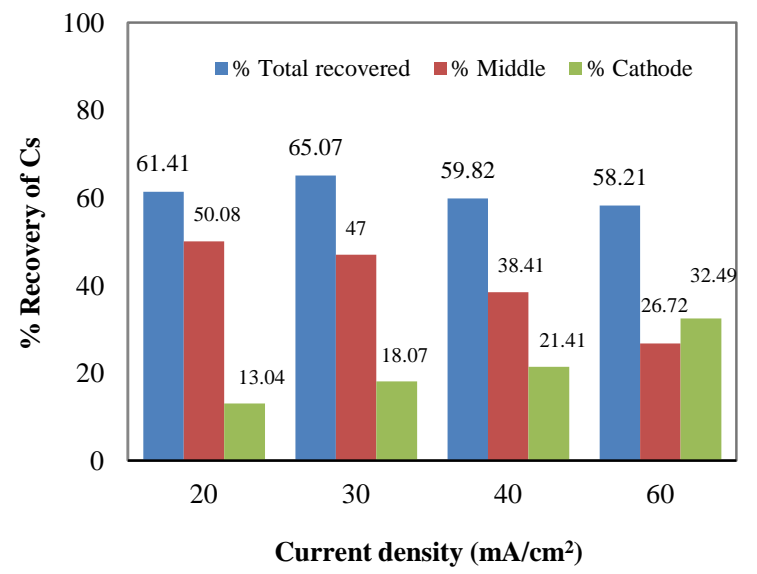

Fig 5 Recovery of cesium from different compartments in mode-II

With increasing current density from $20 \mathrm{~mA} / \mathrm{cm}^{2}$ to 30 $\mathrm{mA} / \mathrm{cm}^{2}$, the total recovery of cesium increased from 61.41 to $64.07 \%$ and further increase in current density from 40 to $60 \mathrm{~mA} / \mathrm{cm}^{2}$ resulted in decrease of recovery. Even though migration of cesium increased from 13.04 to $32.49 \%$ with increase in current density, total recovery decreased.

In electromembrane processes, water splitting results in $\mathrm{H}^{+}$ and $\mathrm{OH}^{-}$formation, at the bipolar interface of the cation exchange resin and the anion ion exchange membrane. Water splitting is more intensive at the anion-exchange membrane(V.V. Nikonenko et al). The generation of $\mathrm{H}^{+}$at the anion ion exchange membrane increased the eluant conductivity (not shown here) after one hour of operation.

The migration diffusion coefficients determined for different current densities were shown in Table 2. The determined diffusion coefficients increased with increase in current densities up to $40 \mathrm{~mA} / \mathrm{cm}^{2}$ and further increase in current density decreased the diffusion coefficients.

Table 2: Migration diffusion coefficients in mode-II

\begin{tabular}{|l|l|l|l|l|}
\hline $\begin{array}{l}\text { Current } \\
\text { density } \\
\left(\mathrm{mA} / \mathrm{cm}^{2}\right)\end{array}$ & $\begin{array}{l}\mathrm{n}_{\max } \\
(\text { moles })\end{array}$ & $\begin{array}{l}\mathrm{k}_{\mathrm{m}} \mathrm{X} 10^{-5} \\
\left(\mathrm{~s}^{-1}\right)\end{array}$ & $\begin{array}{l}\text { grad } \varnothing \\
(\mathrm{V} / \mathrm{m})\end{array}$ & $\begin{array}{l}\mathrm{D}_{\text {eff }} \\
10^{-9} \\
\left(\mathrm{~m}^{2} / \mathrm{s}\right)\end{array}$ \\
\hline 20 & 0.71 & 6.313 & 600 & 1.002 \\
\hline 30 & 1 & 8.145 & 800 & 1.135 \\
\hline 40 & 1.16 & 8.443 & 1000 & 1.407 \\
\hline 60 & 1.7 & 8.547 & 1680 & 1.262 \\
\hline
\end{tabular}

\subsection{Current Efficiency}

The EDI performance can be evaluated in terms of $\mathrm{Cs}^{+}$ recovery in the catholyte and current efficiency yields in terms of $\mathrm{Cs}^{+}$ions. The studied EDI process for Cs recovery from AMP-PAN was effectively assessed by the difference between the initial and final concentration of cesium ions in the resin. On the other hand, the ratio of the quantity of cesium transferred to the cathode compartment and the charge passed during electrodialysis taking into account Faraday's constant, expresses the current efficiency of cesium transport induced by the electrical field.

$$
\mathrm{CE}_{\mathrm{Cs}+}^{\text {catode }}=\frac{\mathrm{z}_{\mathrm{Cu}} \mathrm{F}_{\mathrm{Cs}+}^{\text {cathode }}}{\mathrm{Q}}
$$

where, $\mathrm{n}_{\mathrm{Cs}+}^{\text {cathode }}$ is the number of moles Cs species in the cathode compartment and Q the electrical charge passed at time t. For the present case of constant current operations, the electrical charge is given by: $\mathrm{Q}=\mathrm{I} \mathrm{x} \mathrm{dt}$.

As seen from the Figure 6, the current efficiency was highest during the first hour of operation of the cell and later on it was decreasing with time for all the current densities studied. The initial current efficiency decreased from $23 \%$ to $20 \%$ with decreasing applied current density from 60 to $20 \mathrm{~mA} / \mathrm{cm}^{2}$. 


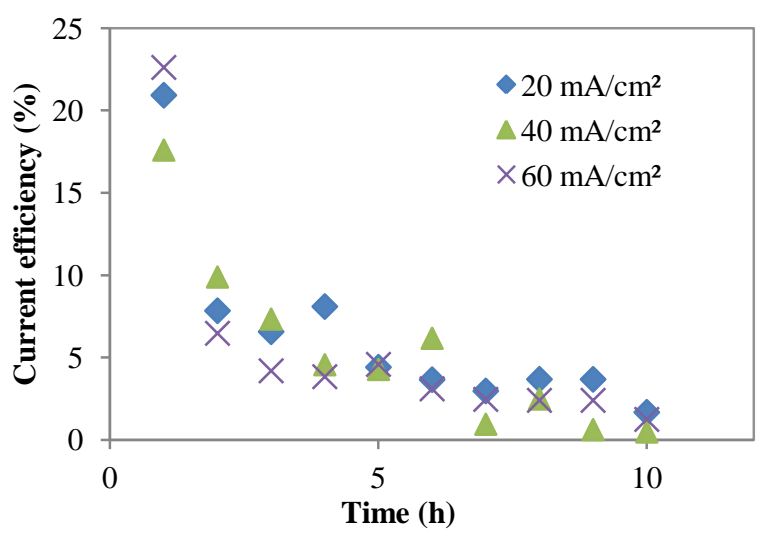

Fig 6 Variation of current efficiency with time for different current densities

\section{CONCLUSION}

Investigations were carried out for recovery of cesium from cesium loaded AMP-PAN by electrodeionisation in two different modes of operation. The eluant was passed as anolyte in mode-I and through a bed of AMP-PAN loaded in the central compartment in mode-II operation of an electrodialysis cell. Cs recovery from the system occurred in two ways, by migration into cathode compartment under the influence of applied voltage and by convection of Cs by the eluant through the central compartment. Effect of current density on the recovery of cesium by both the ways is experimentally determined and using Nernst Plank equation, diffusivities of cesium were estimated. Cesium recovered by convection is negligible in mode-I and is significant in mode-II which further decreased with increase in applied current density. Cesium recoverd by migration in the catholyte results in pure form of cesium.

\section{REFERENCES}

[1] Mahmoud, L. Muhr, S. Vasiluk, A. Aleynikoff, F. Lapicque, Investigation of transport phenomena in a hybrid ion exchange-electrodialysis system for the removal of copper ions. Journal of applied electrochemistry, 2003. 33(10): p. 875-884.

[2] F. Sebesta (1990) Composite ion-exchanger with ammonium molybdophosphate and its properties. J. Radioanal. Nucl. Chem., 140: 15-21.

[3] P.B. Spoor, W.R. Ter Veen, L.J.J. Janssen (2001) Electrodeionization 1: migration of nickel ions absorbed in a rigid, macroporous cation-exchange resin. Journal of Applied Electrochemistry 31(5): 523-530.

[4] P.B. Spoor, W.R. Ter Veen, L.J.J. Janssen (2001) Electrodeionization 2: The migration of nickel ions absorbed in a flexible ion-exchange resin. Journal of applied electrochemistry 31(10):1071-1077.

[5] T.A.Todd, N.R. Mann, T.J. Tranter, F. Šebesta, J. John, A. Motl (2002) Cesium sorption from concentrated acidic tank wastes using ammonium molybdophosphate-polyacrylonitrile composite sorbents. Journal of radioanalytical and nuclear chemistry. 254: 47-52.
[6] T. A. Todd, K.N. Brewer, D. J. Wood, P. A. Tullock, N. R. Mann, L. G. Olson (2001) Evaluation and Testing of Inorganic Ion Exchange Sorbents for the removal of Cesium-137 from Idaho Chemical Processing Plant Acidic Tank Waste. Sep. Sci. Technol., 36: 999-1016.

[7] T.J. Tranter, R.S. Herbst, T.A. Todd, A.L. Olson, H.B. Eldredge, (2002) Evaluation of ammonium molybdophosphate-polyacrylonitrile AMP-PAN as a cesium selective sorbent for the removal of $137 \mathrm{Cs}$ from acidic nuclear waste solutions. Adv. Environ. Res. 6: 107-121.

[8] T.J. Tranter, R.S. Herbst, T.A. Todd, A.L. Olson, H.B. Eldredge, (2003) Application of a second order kinetic model for the preliminary design of an adsorption bed system using ammonium molybdophosphate-polyacrylonitrile for the removal of 137 Cs from acidic nuclear waste solutions. Advances in Environmental Research 7(4): 913-923.

[9] V.V. Nikonenko, A.V. Kovalenko, M.K. Urtenov, N.D. Pismenskaya, J. Han, P. Sistat, G. Pourcelly (2014) Desalination at overlimiting currents: State of the art and perspectives. Desalination 342: 85-106.

[10] Y. Park, Y.C. Lee, W.S. Shin, S.J. Choi (2010) Removal of cobalt, strontium and cesium from radioactive laundry wastewater by ammonium molybdophosphate-polyacrylonitrile (AMP-PAN). Chemical Engineering Journal162(2): 685-695.

[11] Y.S. Dzyazko (2006) Purification of a diluted solution containing nickel using electrodeionization. Desalination198(1-3): 47-55.

[12] Y.S. Dzyazko, L.N. Ponomaryova, L.M. Rozhdestvenskaya, S.L. Vasilyuk, V.N. Belyakov (2014) Electrodeionization of low-concentrated multicomponent Ni2+containing solutions using organic-inorganic ion-exchanger. Desalination 342: 43-51. 